\title{
Bright spots among the world's coral reefs
}

Joshua E. Cinner ${ }^{1}$, Cindy Huchery ${ }^{1}$, M. Aaron MacNeil1,2,3, Nicholas A.J. Graham, ${ }^{1,4}$, Tim R. McClanahan ${ }^{5}$, Joseph Maina ${ }^{5,6,7}$, Eva Maire ${ }^{1,8}$, John N. Kittinger ${ }^{9,10}$, Christina C. Hicks ${ }^{1,4,9}$, Camilo Mora ${ }^{11}$, Edward H. Allison ${ }^{12}$, Stephanie D’Agata ${ }^{5,7,13}$, Andrew Hoey ${ }^{1}$, David A. Feary ${ }^{14}$, Larry Crowder ${ }^{9}$, Ivor D. Williams ${ }^{15}$, Michel Kulbicki ${ }^{16}$, Laurent Vigliola ${ }^{13}$, Laurent Wantiez ${ }^{17}$, Graham Edgar $^{18}$, Rick D. Stuart-Smith ${ }^{18}$, Stuart A. Sandin ${ }^{19}$, Alison L. Green ${ }^{20}$, Marah J. Hardt ${ }^{21}$, Maria Beger ${ }^{6}$, Alan Friedlander ${ }^{22,23}$, Stuart J. Campbel1 ${ }^{5}$, Katherine E. Holmes ${ }^{5}$, Shaun K. Wilson ${ }^{24,25}$, Eran Brokovich ${ }^{26}$, Andrew J. Brooks ${ }^{27}$, Juan J. Cruz-Motta ${ }^{28}$, David J. Booth ${ }^{29}$, Pascale Chabanet ${ }^{30}$, Charlie Gough ${ }^{31}$, Mark Tupper ${ }^{32}$, Sebastian C. A. Ferse ${ }^{33}$, U. Rashid Sumaila ${ }^{34} \&$ David Mouillot ${ }^{1,8}$

Ongoing declines in the structure and function of the world's coral reefs ${ }^{1,2}$ require novel approaches to sustain these ecosystems and the millions of people who depend on them ${ }^{3}$. A presently unexplored approach that draws on theory and practice in human health and rural development ${ }^{4,5}$ is to systematically identify and learn from the 'outliers'-places where ecosystems are substantially better ('bright spots') or worse ('dark spots') than expected, given the environmental conditions and socioeconomic drivers they are exposed to. Here we compile data from more than 2,500 reefs worldwide and develop a Bayesian hierarchical model to generate expectations of how standing stocks of reef fish biomass are related to 18 socioeconomic drivers and environmental conditions. We identify 15 bright spots and 35 dark spots among our global survey of coral reefs, defined as sites that have biomass levels more than two standard deviations from expectations. Importantly, bright spots are not simply comprised of remote areas with low fishing pressure; they include localities where human populations and use of ecosystem resources is high, potentially providing insights into how communities have successfully confronted strong drivers of change. Conversely, dark spots are not necessarily the sites with the lowest absolute biomass and even include some remote, uninhabited locations often considered near pristine ${ }^{6}$. We surveyed local experts about social, institutional, and environmental conditions at these sites to reveal that bright spots are characterized by strong sociocultural institutions such as customary taboos and marine tenure, high levels of local engagement in management, high dependence on marine resources, and beneficial environmental conditions such as deep-water refuges. Alternatively, dark spots are characterized by intensive capture and storage technology and a recent history of environmental shocks. Our results suggest that investments in strengthening fisheries governance, particularly aspects such as participation and property rights, could facilitate innovative conservation actions that help communities defy expectations of global reef degradation.

Despite substantial international conservation efforts, diversity and abundance continue to decline within many of the world's ecosystems ${ }^{1,7}$. Most conservation approaches aim to identify and protect places of high ecological integrity under minimal threat ${ }^{8}$. Yet, with escalating social and environmental drivers of change, conservation actions are also needed where people and nature coexist, especially where human effects are already severe ${ }^{9}$. Here, we highlight an approach for implementing conservation in coupled human-natural systems focused on identifying and learning from outliers-places that are performing substantially better than expected, given the socioeconomic and environmental conditions they are exposed to. By their very nature, outliers deviate from expectations, and consequently can provide novel insights into confronting complex problems where conventional solutions have failed. This type of positive deviance, or bright spot analysis has been used in fields such as business, health, and human development to uncover local actions and governance systems that work in the context of widespread failure ${ }^{10,11}$, and holds much promise in informing conservation.

To demonstrate this approach, we compiled data from 2,514 coral reefs in 46 countries, states, and territories (hereafter 'nations/states') and developed a Bayesian hierarchical model to generate expected conditions of how standing reef fish biomass (a key indicator of resource availability and ecosystem functions ${ }^{12}$ ) was related to 18 key environmental variables and socioeconomic drivers (Fig. 1; Extended Data Tables 1-4; Extended Data Figs 1-3; Methods). Drawing on a broad body of theoretical and empirical research in the social sciences ${ }^{13-15}$ and ecology $y^{2,6,16}$ on coupled human-natural systems, we quantified how reef fish biomass (Fig. 1a) was related to distal social drivers such as markets, affluence, governance, and population (Fig. 1b, c), while controlling for well-known environmental conditions such as depth,

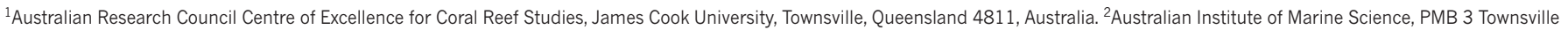
MC, Townsville, Queensland 4810, Australia. ${ }^{3}$ Department of Mathematics and Statistics, Dalhousie University, Halifax, Nova Scotia B3H 3J5 Canada. ${ }^{4}$ Lancaster Environment Centre, Lancaster University, Lancaster LA1 4YQ, UK. ${ }^{5}$ Wildlife Conservation Society, Global Marine Program, Bronx, New York 10460, USA. ${ }^{6}$ Australian Research Council Centre of Excellence for Environmental Decisions, Centre for Biodiversity and Conservation Science, University of Queensland, Brisbane St Lucia, Queensland 4074, Australia. ${ }^{7}$ Department of Environmental Sciences, Macquarie

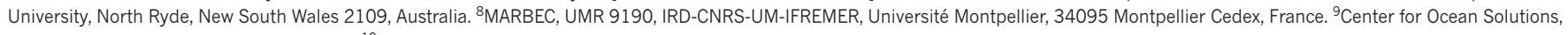
Stanford University, California 94305, USA. ${ }^{10}$ Conservation International Hawaii, Betty and Gordon Moore Center for Science and Oceans, 7192 Kalaniana'ole Hwy, Suite G230, Honolulu, Hawaii 96825, USA. ${ }^{11}$ Department of Geography, University of Hawaii at Manoa, Honolulu, Hawaii 96822, USA. ${ }^{12}$ School of Marine and Environmental Affairs, University of Washington, Seattle,

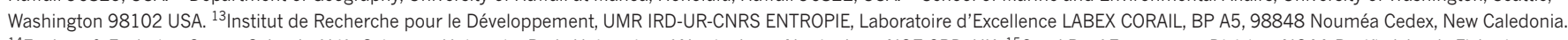
${ }^{14}$ Ecology \& Evolution Group, School of Life Sciences, University Park, University of Nottingham, Nottingham NG7 2RD, UK. ${ }^{15}$ Coral Reef Ecosystems Division, NOAA Pacific Islands Fisheries Science Center, Honolulu, Hawaii 96818, USA. ${ }^{16}$ UMR Entropie, Labex Corail, -IRD, Université de Perpignan, 66000 Perpignan, France. ${ }^{17}$ EA4243 LIVE, University of New Caledonia, BPR4 98851 Nouméa Cedex, New Caledonia. ${ }^{18}$ Institute for Marine and Antarctic Studies, University of Tasmania, Hobart, Tasmania 7001, Australia. ${ }^{19}$ Scripps Institution of Oceanography, University of

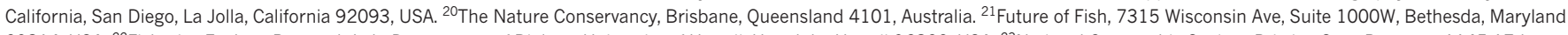
20814, USA. ${ }^{22}$ Fisheries Ecology Research Lab, Department of Biology, University of Hawaii, Honolulu, Hawaii 96822 , USA. ${ }^{23}$ National Geographic Society, Pristine Seas Program, 114517 th Street NW, Washington DC 20036-4688, USA. ${ }^{24}$ Department of Parks and Wildlife, Kensington, Perth, Western Australia 6151 , Australia. ${ }^{25}$ Oceans Institute, University of Western Australia, Crawley, Western Australia 6009, Australia. ${ }^{26}$ The Israeli Society of Ecology and Environmental Sciences, Kehilat New York 19 Tel Aviv, Israel. ${ }^{27}$ Marine Science Institute, University of California,

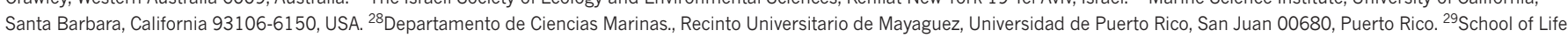

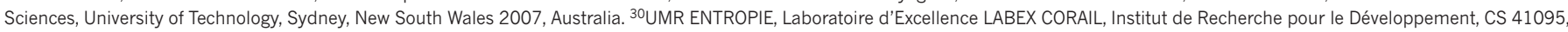

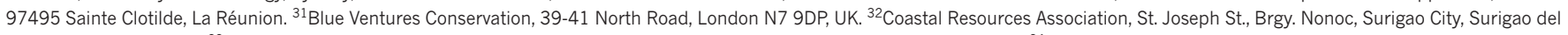

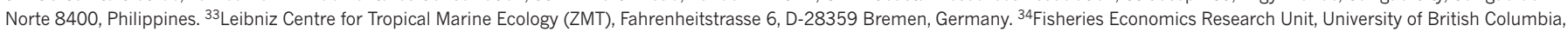
2202 Main Mall, Vancouver, British Columbia V6T 1Z4, Canada. 
a

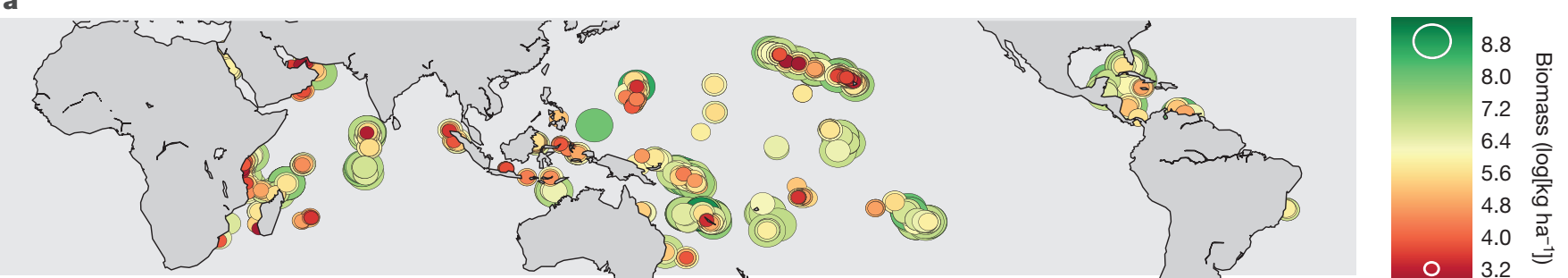

b

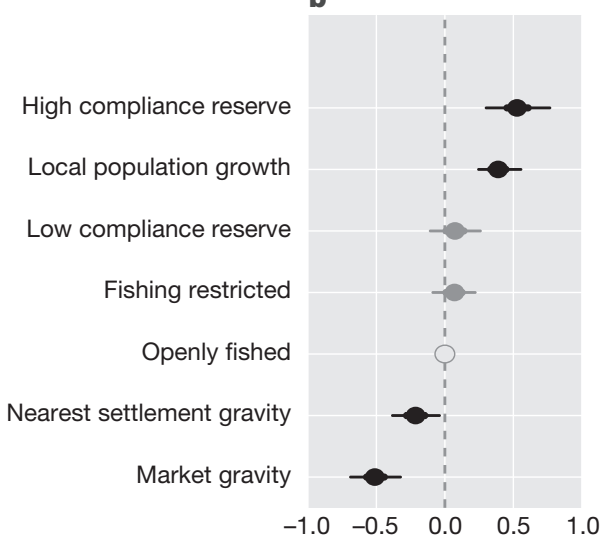

Figure 1 | Global patterns and drivers of reef fish biomass. a, Reef fish biomass among 918 study sites. Points vary in size and colour proportional to the amount of fish biomass. b-d, Standardized effect size of localscale social drivers, nation/state-scale social drivers, and environmental covariates, respectively. Parameter estimates are Bayesian posterior median

habitat, and productivity (Fig. 1d) (Extended Data Table 1; Methods). In contrast to many global studies of reef systems that are focused on demonstrating the severity of human effects ${ }^{6}$, our examination seeks c

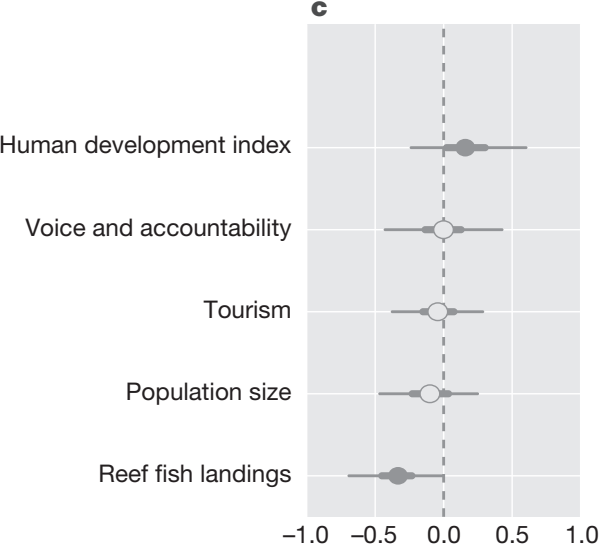

Standardized effect size

values, 95\% uncertainty intervals (UI; thin lines), and 50\% UI (thick lines). Black dots indicate that the $95 \%$ UI does not overlap 0; grey closed circles indicates that $75 \%$ of the posterior distribution lies to one side of 0 ; and grey open circles indicate that the $50 \%$ UI overlaps 0 .

to uncover potential policy levers by highlighting the relative role of specific social drivers. A key finding from our global analysis is that our metric of potential interactions with urban centres, called market

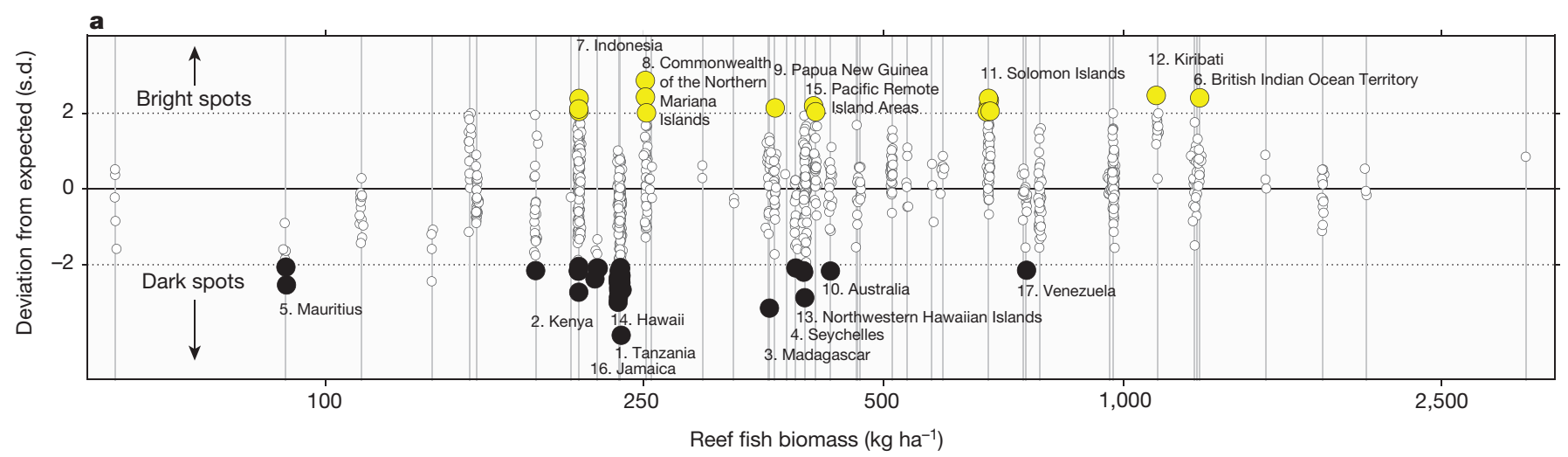

b

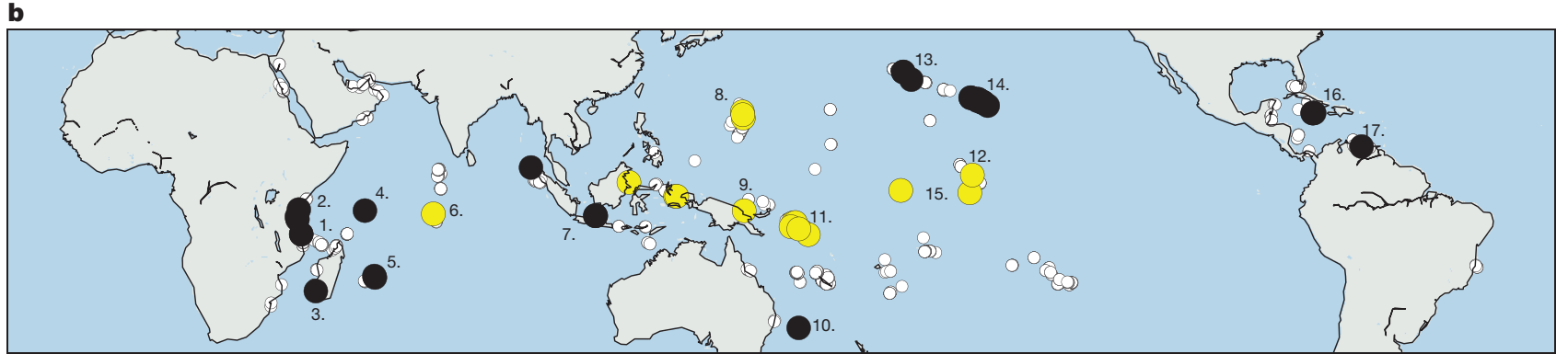

Figure 2 | Bright and dark spots among the world's coral reefs. a, Each site's deviation from expected biomass ( $y$ axis) along a gradient of nation/ state mean biomass ( $x$ axis). The 50 sites with biomass values $>2$ standard deviations above or below expected values were considered bright (yellow) and dark (black) spots, respectively. Each grey vertical line represents a nation/state; those with bright or dark spots are labelled and numbered. There can be multiple bright or dark spots in each nation/state. b, Map highlighting bright and dark spots with large circles, and other sites in small circles. Numbers correspond to panel a. 

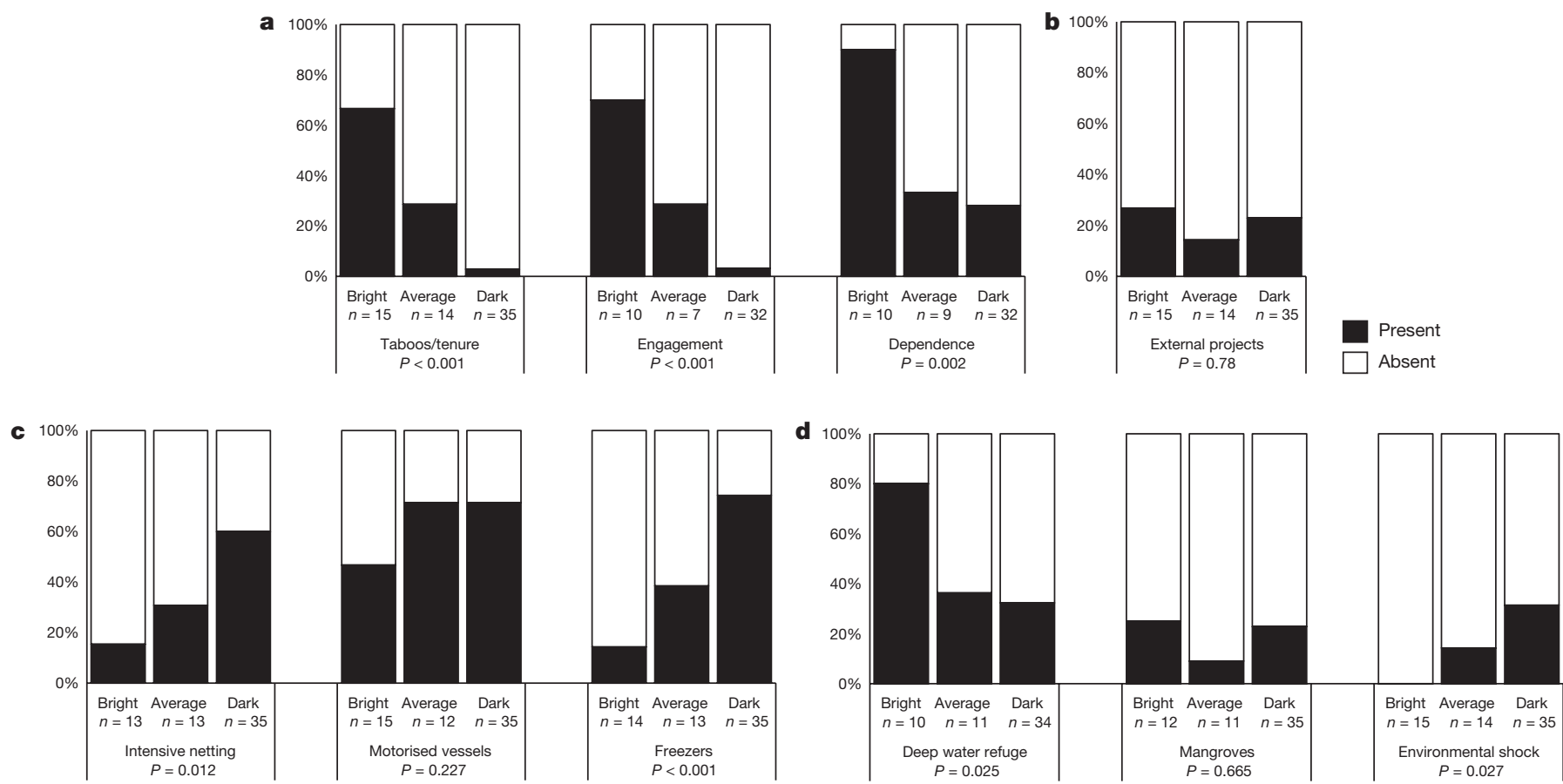

Figure 3 | Differences in key social and environmental conditions between bright spots, dark spots, and 'average' sites. a, Social and institutional conditions; $\mathbf{b}$, external- or donor-driven projects; c, technologies; d, environmental conditions. $P$ values are determined using Fisher's exact test. Intensive netting includes beach seine nets, surround gill nets, and muro-ami.

gravity $^{17}$ (Methods), more so than local or national population pressure, management, environmental conditions, or national socioeconomic context, had the strongest relationship with reef fish biomass (Fig. 1). Specifically, we found that reef fish biomass decreased as the size and accessibility of markets increased (Extended Data Fig. 1b). Somewhat counter-intuitively, fish biomass was higher in places with high local human population growth rates, probably reflecting human migration to areas of better environmental quality ${ }^{18}$ - a phenomenon that could result in increased degradation at these sites over time. We found a strong positive, but less certain relationship (that is, a high standardized effect size, but only $>75 \%$ of the posterior distribution above zero) with the Human Development Index, meaning that reefs tended to be in better condition in wealthier nations/states (Fig. 1c). Our analysis also confirmed the role that marine reserves can play in sustaining biomass on coral reefs, but only when compliance is high (Fig. 1b), reinforcing the importance of fostering compliance for reserves to be successful.

Next, we identified 15 bright spots and 35 dark spots among the world's coral reefs, defined as sites with biomass levels more than two standard deviations higher or lower than expectations from our global model, respectively (Fig. 2; Methods; Extended Data Table 5). Rather than simply identifying places in the best or worst condition, our bright spots approach reveals the places that most strongly defy expectations. Using them to inform the conservation discourse will certainly challenge established ideas of where and how conservation efforts should be focused. For example, remote places far from human impacts are conventionally considered near-pristine areas of high conservation value $^{6}$, yet most of the bright spots we identified occur in fished, populated areas (Extended Data Table 5), some with biomass values below the global average. Alternatively, some remote places such as parts of the northwest Hawaiian Islands underperform (that is, were identified as dark spots).

Detailed analysis of why bright spots can evade the fate of similar areas facing equivalent stresses will require a new research agenda gathering detailed site-level information on social and institutional conditions, technological innovations, external influences, and ecological processes ${ }^{19}$ that are simply not available in a global-scale analysis. As a hypothesis-generating exploration to begin uncovering why bright and dark spots may diverge from expectations, we surveyed data providers who sampled the sites and other experts with first-hand knowledge about the presence or absence of ten key social and environmental conditions at the 15 bright spots, 35 dark spots, and 14 average sites with biomass values closest to model expectations (see Methods and Supplementary Information for details). Our initial exploration revealed that bright spots were more likely to have high levels of local engagement in the management process, high dependence on coastal resources, and the presence of sociocultural governance institutions such as customary tenure or taboos (Fig. 3; Methods). For example, in one bright spot, Karkar Island, Papua New Guinea, resource use is restricted through an adaptive rotational harvest system based on ecological feedbacks, marine tenure that allows for the exclusion of fishers from outside the local village, and initiation rights that limit individuals' entry into certain fisheries ${ }^{20}$. Bright spots were also generally proximate to deep water, which may help provide a refuge from disturbance for corals and fish ${ }^{21}$ (Fig. 3; Extended Data Fig. 4). Conversely, dark spots were distinguished by having fishing technologies allowing for more intensive exploitation, such as fish freezers and potentially destructive netting, as well as a recent history of environmental shocks (for example, coral bleaching or cyclone; Fig. 3). The latter is particularly worrisome in the context of climate change, which is likely to lead to increased coral bleaching and more intense cyclones ${ }^{22}$.

Our global analyses highlight two novel opportunities to inform coral reef governance. The first is to use bright spots as agents of change to expand the conservation discourse from the current focus on protecting places under minimal threat ${ }^{8}$, towards harnessing lessons from places that have successfully confronted numerous or severe stressors. Our bright spots approach can be used to inform the types of investments and governance structures that may help to create more sustainable pathways for impacted coral reefs. Specifically, our initial investigation highlights how investments that strengthen fisheries governance, particularly issues such as participation and property rights, could help communities to innovate in ways that allow them to defy expectations. Conversely, the more typical efforts to provide capture and storage infrastructure, particularly where there are environmental shocks and local-scale governance is weak, may lead to 
social-ecological traps ${ }^{23}$ that reinforce resource degradation beyond expectations. Effectively harnessing the potential to learn from both bright and dark spots will require scientists to increase research efforts in these places, NGOs to catalyse lessons from other areas, donors to start investing in novel solutions, and policy makers to ensure that governance structures foster flexible learning and experimentation. Indeed, bright spots may have much to offer in terms of how to creatively confront drivers of change and prioritize conservation actions. Likewise, dark spots can help identify development strategies to avoid. Critically, the bright spots we identified span the development spectrum from low to high income (for example, Solomon Islands and territories of the USA, respectively; Fig. 2), showing that lessons about effective reef management can emerge from diverse places.

A second opportunity stems from a renewed focus on managing the socioeconomic drivers that shape reef conditions. Many social drivers are amenable to governance interventions, and our comprehensive analysis (Fig. 1) suggests that an increased policy focus on social drivers such as markets and development could result in improvements to reef fish biomass. For example, given the important influence of markets in our analysis, reef managers, donor organizations, conservation groups, and coastal communities could improve sustainability by developing interventions that dampen the negative influence of markets on reef systems. A portfolio of market interventions, including eco-labelling and sustainable harvesting certifications, fisheries improvement projects, and value chain interventions have been developed within large-scale industrial fisheries to condition access to markets based on sustainable harvesting ${ }^{24,25}$. Although there is considerable scope for adapting these interventions to artisanal coral reef fisheries in both local and regional markets, effectively dampening the negative influence of markets may also require developing novel interventions that address the range of ways in which markets can lead to overexploitation. Existing research suggests that markets create incentives for overexploitation not only by affecting price and price variability for reef products ${ }^{26}$, but also by influencing people's behaviour ${ }^{27,28}$, including their willingness to cooperate in the collective management of natural resources ${ }^{29}$.

The long-term viability of coral reefs will ultimately depend on international action to reduce carbon emissions ${ }^{22}$. However, fisheries remain a pervasive source of reef degradation, and effective local-level fisheries governance is crucial to sustaining ecological processes that give reefs the best chance of coping with global environmental change ${ }^{30}$. Seeking out and learning from bright spots is a novel approach to conservation that may offer insights into confronting the complex governance problems facing coupled human-natural systems such as coral reefs.

Online Content Methods, along with any additional Extended Data display items and Source Data, are available in the online version of the paper; references unique to these sections appear only in the online paper.

\section{Received 5 January; accepted 27 May 2016.}

Published online 15 June 2016.

1. Pandolfi, J. M. et al. Global trajectories of the long-term decline of coral reef ecosystems. Science 301, 955-958 (2003).

2. Bellwood, D. R., Hughes, T. P., Folke, C. \& Nyström, M. Confronting the coral reef crisis. Nature 429, 827-833 (2004).

3. Hughes, T. P., Bellwood, D. R., Folke, C., Steneck, R. S. \& Wilson, J. New paradigms for supporting the resilience of marine ecosystems. Trends Ecol. Evol. 20, 380-386 (2005)

4. Sternin, M. et al. in The Hearth Nutrition Model: Applications in Haiti, Vietnam, and Bangladesh. (eds O Wollinka, E Keeley, B Burkhalter, \& N Bashir) 49-61 (VA: BASICS, 1997).

5. Pretty, J. N. et al. Resource-conserving agriculture increases yields in developing countries. Environ. Sci. Technol. 40, 1114-1119 (2006).

6. Knowlton, N. \& Jackson, J. B. C. Shifting baselines, local impacts, and global change on coral reefs. PLoS Biol. 6, e54 (2008).
7. Naeem, S., Duffy, J. E. \& Zavaleta, E. The functions of biological diversity in an age of extinction. Science 336, 1401-1406 (2012).

8. Devillers, R. et al. Reinventing residual reserves in the sea: are we favouring ease of establishment over need for protection? Aquat. Conserv. 25, 480-504 (2014).

9. Pressey, R. L., Visconti, P. \& Ferraro, P. J. Making parks make a difference: poor alignment of policy, planning and management with protected-area impact, and ways forward. Philos. Trans. R. Soc. B 370, 20140280 (2015).

10. Pascale, R. T. \& Sternin, J. Your company's secret change agents. Harv. Bus. Rev. 83, 72-81, 153 (2005).

11. Levinson, F. J., Barney, J., Bassett, L. \& Schultink, W. Utilization of positive deviance analysis in evaluating community-based nutrition programs: an application to the Dular program in Bihar, India. Food Nutr. Bull. 28, 259-265 (2007).

12. McClanahan, T. R. et al. Critical thresholds and tangible targets for ecosystembased management of coral reef fisheries. Proc. Natl Acad. Sci. USA 108, 17230-17233 (2011).

13. York, R. et al. Footprints on the earth: The environmental consequences of modernity. Am. Sociol. Rev. 68, 279-300 (2003).

14. Lambin, E. F. et al. The causes of land-use and land-cover change: moving beyond the myths. Glob. Environ. Change 11, 261-269 (2001)

15. Cinner, J. E. et al. Comanagement of coral reef social-ecological systems. Proc. Natl Acad. Sci. USA 109, 5219-5222 (2012).

16. Hughes, T. P., Huang, H. \& Young, M. A. The wicked problem of China's disappearing coral reefs. Conserv. Biol. 27, 261-269 (2013).

17. Dodd, S. C. The interactance hypothesis: a gravity model fitting physical masses and human groups. Am. Sociol. Rev. 15, 245-256 (1950).

18. Wittemyer, G., Elsen, P., Bean, W. T., Burton, A. C. \& Brashares, J. S. Accelerated human population growth at protected area edges. Science 321, 123-126 (2008)

19. Noble, A. et al. in Bright spots demonstrate community successes in African agriculture (ed. F. W. T. Penning de Vries) 7 (International Water Management Institute, 2005)

20. Cinner, J. et al. Periodic closures as adaptive coral reef management in the Indo-Pacific. Ecol. Soc. 11, 31 (2006).

21. Lindfield, S. J. et al. Mesophotic depths as refuge areas for fishery-targeted species on coral reefs. Coral Reefs 35, 125-137 (2016).

22. Cinner, J. E. et al. A framework for understanding climate change impacts on coral reef social-ecological systems. Reg. Environ. Change 16, 1133-1146 (2016).

23. Cinner, J. E. Social-ecological traps in reef fisheries. Glob. Environ. Change 21, 835-839 (2011).

24. O'Rourke, D. The science of sustainable supply chains. Science $\mathbf{3 4 4}$, 1124-1127 (2014)

25. Sampson, G. S. et al. Sustainability. Secure sustainable seafood from developing countries. Science 348, 504-506 (2015)

26. Schmitt, K. M. \& Kramer, D. B. Road development and market access on Nicaragua's Atlantic coast: implications for household fishing and farming practices. Environ. Conserv. 36, 289-300 (2009)

27. Falk, A. \& Szech, N. Morals and markets. Science 340, 707-711 (2013).

28. Sandel, M. J. What Money Can't Buy: The Moral Limits Of Markets. (Macmillan, 2012).

29. Ostrom, E. Governing the Commons: The Evolution of Institutions for Collective Action. (Cambridge University Press, 1990).

30. Graham, N. A., Jennings, S., MacNeil, M. A., Mouillot, D. \& Wilson, S. K Predicting climate-driven regime shifts versus rebound potential in coral reefs. Nature 518, 94-97 (2015).

Supplementary Information is available in the online version of the paper.

Acknowledgements The ARC Centre of Excellence for Coral Reef Studies, Stanford University, and University of Montpellier funded working group meetings. This work was supported by J.E.C.'s Pew Fellowship in Marine Conservation and ARC Australian Research Fellowship. Thanks to M. Barnes for constructive comments.

Author Contributions J.E.C. conceived of the study with support from M.A.M. N.A.J.G., T.R.M., J.K., C.Hu., D.M., C.M., E.H.A., and C.C.Hi.; C.Hu. managed the database; M.A.M., J.E.C., and D.M. developed and implemented the analyses; J.E.C. led the manuscript with M.A.M. and N.A.J.G. All other authors contributed data and made substantive contributions to the text.

Author Information This is the Social-Ecological Research Frontiers (SERF) working group contribution no. 11. Reprints and permissions information is available at www.nature.com/reprints. The authors declare no competing financial interests. Readers are welcome to comment on the online version of the paper. Correspondence and requests for materials should be addressed to J.E.C. (Joshua.cinner@jcu.edu.au).

Reviewer Information Nature thanks S. Qian, B. Walker and the other anonymous reviewer(s) for their contribution to the peer review of this work. 


\section{METHODS}

No statistical methods were used to predetermine sample size.

Scales of data. Our data were organized at three spatial scales:

(i) Reef $(n=2,514)$. The smallest scale, which had an average of 2.4 surveys/ transects.

(ii) Site (a cluster of reefs; $n=918$ ). We clustered reefs together that were within $4 \mathrm{~km}$ of each other, and used the centroid of these clusters to estimate site-level social and site-level environmental covariates (Extended Data Table 1). To make these clusters, we first estimated the linear distance between all reefs, then used a hierarchical analysis with the completelinkage clustering technique based on the maximum distance between reefs. We set the cut-off at $4 \mathrm{~km}$ to select mutually exclusive sites where reefs cannot be more distant than $4 \mathrm{~km}$. The choice of $4 \mathrm{~km}$ was informed by a 3 -year study of the spatial movement patterns of artisanal coral reef fishers, corresponding to the highest density of fishing activities on reefs based on GPS-derived effort density maps of artisanal coral reef fishing activities ${ }^{31}$. This clustering analysis was carried out using the $\mathrm{R}$ functions hclust and cutree, resulting in an average of 2.7 reefs per site.

(iii) Nation/state (nation, state, or territory; $n=46$ ). A larger scale in our analysis was nation/state, which are jurisdictions that generally correspond to individual nations (but could also include states, territories, overseas regions, or extremely remote areas within a state such as the northwest Hawaiian Islands; Extended Data Table 2), within which sites and reefs were nested for analysis.

Estimating biomass. Reef fish biomass can reflect a broad selection of reef fish functioning and benthic conditions ${ }^{12,32-34}$, and is a key metric of resource availability for reef fisheries. Reef fish biomass estimates were based on instantaneous visual counts from 6,088 surveys collected from 2,514 reefs. All surveys used standard belt-transects, distance sampling, or point-counts, and were conducted between 2004 and 2013. Where data from multiple years were available from a single reef, we included only data from the year closest to 2010 . Within each survey area, reef associated fishes were identified to species level, abundance counted, and total length (TL) estimated, with the exception of one data provider who measured biomass at the family level. To make estimates of biomass from these transect-level data comparable among studies, we:

(iv) Retained families that were consistently studied and were above a minimum size cut-off. Thus, we retained counts of $>10-\mathrm{cm}$ diurnally active, non-cryptic reef fish that are resident on the reef (20 families, 774 species), excluding sharks and semi-pelagic species. We also excluded three groups of fishes that are strongly associated with coral habitat conditions and are rarely targets for fisheries (Anthiinae, Chaetodontidae, and Cirrhitidae). Families included are: Acanthuridae, Balistidae, Diodontidae, Ephippidae, Haemulidae, Kyphosidae, Labridae, Lethrinidae, Lutjanidae, Monacanthidae, Mullidae, Nemipteridae, Pinguipedidae, Pomacanthidae, Serranidae, Siganidae, Sparidae, Synodontidae, Tetraodontidae and Zanclidae. We calculated the total biomass of fish on each reef using standard published species-level length-weight relationship parameters or those available on FishBase $^{35}$. When length-weight relationship parameters were not available for a species, we used the parameters for a closely related species or genus.

(v) Directly accounted for depth and habitat as covariates in the model (see Environmental conditions section below).

(vi) Accounted for any potential bias among data providers (capturing information on both inter-observer differences, and census methods) by including each data provider as a random effect in our model.

Biomass means, medians, and standard deviations were calculated at the reefscale. All reported log values are the natural log.

\section{Social drivers}

Local population growth. We created a $100 \mathrm{~km}$ buffer around each site and used this to calculate human population within the buffer in 2000 and 2010 based on the Socioeconomic Data and Application Centre (SEDAC) gridded population of the world database ${ }^{36}$. Population growth was the proportional difference between the population in 2000 and 2010 . We chose a $100 \mathrm{~km}$ buffer as a reasonable range at which many key human impacts from population (for example, land-use and nutrients) might affect reefs ${ }^{37}$.

Management. For each site, we determined if it was unfished, that is, whether it fell within the borders of a no-take marine reserve (we asked data providers to further classify whether the reserve had high or low levels of compliance); restricted-whether there were active restrictions on gears (for example, bans on the use of nets, spear guns, or traps) or fishing effort (which could have included areas inside marine parks that were not necessarily no take); or fished, that is, regularly fished without effective restrictions. To determine these classifications, we used the expert opinion of the data providers, and triangulated this with a global database of marine reserve boundaries ${ }^{38}$.

Gravity. We adapted the economic geography concept of 'gravity ${ }^{17,39-41}$, also called interactance ${ }^{42}$, to examine potential interactions between reefs and: (i) major urban centres/markets (defined as provincial capital cities, major population centres, landmark cities, national capitals, and ports); and (ii) the nearest human settlements. This application of the gravity concept infers that potential interactions increase with population size, but decay exponentially with the effective distance between two points. Thus, we gathered data on both population estimates and a surrogate for distance: travel time.

Population estimations. We gathered population estimates for: (i) the nearest major markets (which includes national capitals, provincial capitals, major population centres, ports, and landmark cities) using the World Cities base map from ESRI; and (ii) the nearest human settlement within a $500 \mathrm{~km}$ radius using LandScan 2011 database. The different data sets were required because the latter is available in raster format while the former is available as point data. We chose a $500 \mathrm{~km}$ radius from the nearest settlement as the maximum distance any non-market fishing activities for fresh reef fish are likely to occur.

Travel time calculation. Travel time was computed using a cost-distance algorithm that computes the least 'cost' (in minutes) of travelling between two locations on a regular raster grid. In our case, the two locations were either the centroid of the site (that is, reef cluster) and the nearest settlement, or the centroid of the site and the major market. The cost (that is, time) of travelling between the two locations was determined by using a raster grid of land cover and road networks with the cells containing values that represent the time required to travel across them ${ }^{43}$ :

- Tree cover, broadleaved, deciduous and evergreen, closed; regularly flooded tree cover, shrub, or herbaceous cover (fresh, saline, \& brackish water) $=$ speed of $1 \mathrm{kmh}^{-1}$

- Tree cover, broadleaved, deciduous, open (open $=15-40 \%$ tree cover $)=$ speed of $1.25 \mathrm{~km} \mathrm{~h}^{-1}$

- Tree cover, needle-leaved, deciduous and evergreen, mixed leaf type; shrub cover, closed-open, deciduous and evergreen; herbaceous cover, closed-open; cultivated and managed areas; mosaic: cropland/tree cover/other natural vegetation, cropland/shrub or grass cover $=$ speed of $1.5 \mathrm{~km} \mathrm{~h}^{-1}$

- Mosaic: tree cover/other natural vegetation; tree cover, burnt $=$ speed of $1.25 \mathrm{~km} \mathrm{~h}^{-1}$

- Sparse herbaceous or sparse shrub cover $=$ speed of $2.5 \mathrm{kmh}^{-1}$

- Water $=$ speed of $20 \mathrm{~km} \mathrm{~h}^{-1}$

- Roads $=$ speed of $60 \mathrm{~km} \mathrm{~h}^{-1}$

- $T r a c k=$ speed of $30 \mathrm{~km} \mathrm{~h}^{-1}$

- Artificial surfaces and associated areas $=$ speed of $30 \mathrm{~km} \mathrm{~h}^{-1}$

- Missing values $=$ speed of $1.4 \mathrm{~km} \mathrm{~h}^{-1}$

We termed this raster grid a friction-surface (with the time required to travel across different types of surfaces analogous to different levels of friction). To develop the friction-surface, we used global data sets of road networks, land cover, and shorelines:

- Road network data was extracted from the Vector Map Level 0 (VMap0) from the National Imagery and Mapping Agency's (NIMA) Digital Chart of the World (DCW). We converted vector data from VMap0 to $1 \mathrm{~km}$ resolution raster.

- Land cover data were extracted from the Global Land Cover 2000 (ref. 44).

- To define the shorelines, we used the GSHHS (Global Self-consistent, Hierarchical, High-resolution Shoreline) database version 2.2.2.

These three friction components (road networks, land cover, and water bodies) were combined into a single friction surface with a Behrmann map projection. We calculated our cost-distance models in $\mathrm{R}^{45}$ using the accCost function of the gdistance package. The function uses Dijkstra's algorithm to calculate least-cost distance between two cells on the grid and the associated distance taking into account obstacles and the local friction of the landscape ${ }^{46}$. Travel time estimates over a particular surface could be affected by the infrastructure (for example, road quality) and types of technology used (for example, types of boats). These types of data were not available at a global scale but could be important modifications in more localized studies.

Gravity computation. To compute the gravity to the nearest market, we calculated the population of the nearest major market and divided that by the squared travel time between the market and the site. Although other exponents can be used ${ }^{47}$, we used the squared distance (or in our case, travel time), which is relatively common in geography and economics. This decay function could be influenced by local considerations, such as infrastructure quality (for example, roads), the types of transport technology (that is, vessels being used), and fuel prices, which were not 
available in a comparable format for this global analysis, but could be important considerations in more localized adaptations of this study.

To determine the gravity of the nearest settlement, we located the nearest populated pixel within $500 \mathrm{~km}$, determined the population of that pixel, and divided that by the squared travel time between that cell and the reef site.

As is standard practice in many agricultural economics studies ${ }^{48}$, an assumption in our study is that the nearest major capital or landmark city represents a market. Ideally we would have used a global database of all local and regional markets for coral reef fish, but this type of database is not available at a global scale. As a sensitivity analysis to help justify our assumption that capital and landmark cities were a reasonable proxy for reef fish markets, we tested a series of candidate models that predicted biomass based on: (1) cumulative gravity of all cities within $500 \mathrm{~km}$ (2) gravity of the nearest city; (3) travel time to the nearest city; (4) population of the nearest city; (5) gravity to the nearest human population above 40 people $\mathrm{km}^{-2}$ (assumed to be a small peri-urban area and potential local market); (6) the travel time between the reef and a small peri-urban area; (7) the population size of the small peri-urban population; (8) gravity to the nearest human population above 75 people $\mathrm{km}^{-2}$ (assumed to be a large peri-urban area and potential market); (9) the travel time between the reef and this large peri-urban population; (10) the population size of this large peri-urban population; and (11) the total population size within a $500 \mathrm{~km}$ radius. Model selection revealed that the best two models were gravity of the nearest city and gravity of all cities within $500 \mathrm{~km}$ (with a 3 AIC value difference between them; Extended Data Table 3). Importantly, when looking at the individual components of gravity models, the travel time components all had a much lower AIC value than the population components, which is broadly consistent with previous systematic review studies ${ }^{49}$. Similarly, travel time to the nearest city had a lower AIC score than any aspect of either the peri-urban or urban measures. This suggests our use of capital and landmark cities is likely to better capture exploitation drivers from markets rather than simple population pressures. This may be because market dynamics are difficult to capture by population threshold estimates; for example some small provincial capitals where fish markets are located have very low population densities, while some larger population centres may not have a market. Downscaled regional or local analyses could attempt to use more detailed knowledge about fish markets, but we used the best proxy available at a global scale

Human Development Index (HDI). HDI is a summary measure of human development encompassing: a long and healthy life, being knowledgeable, and having a decent standard of living. In cases where HDI values were not available specific to the State (for example, Florida and Hawaii), we used the national (for example USA) HDI value.

Population size. For each nation/state, we determined the size of the human population. Data were derived mainly from census reports, the CIA fact book, and Wikipedia.

Tourism. We examined tourist arrivals relative to the nation/state population size (above). Tourism arrivals were gathered primarily from the World Tourism Organization's Compendium of Tourism Statistics.

National reef fish landings. Catch data were obtained from the Sea Around Us Project (SAUP) catch database (http://www.seaaroundus.org), except for Florida, which was not reported separately in the database. We identified 200 reef fish species and taxon groups in the SAUP catch database ${ }^{50}$. Note that reef-associated pelagics such as scombrids and carangids normally form part of reef fish catches. However, we chose not to include these species because they are also targeted and caught in large amounts by large-scale, non-reef operations.

Voice and accountability. This metric, from the World Bank survey on governance, reflects the perceptions of the extent to which a country's citizens are able to participate in selecting their government, as well as freedom of expression, freedom of association, and a free media. In cases where governance values were not available specific to the nation/state (for example, Florida and Hawaii), we used national (for example, USA) values.

Environmental drivers

Depth. The depth of reef surveys were grouped into the following categories: $<4 \mathrm{~m}$, $4-10 \mathrm{~m},>10 \mathrm{~m}$ to account for broad differences in reef fish community structure attributable to a number of inter-linked depth-related factors. Categories were necessary to standardise methods used by data providers and were determined by pre-existing categories used by several data providers.

Habitat. We included the following habitat categories:

(i) Slope. The reef slope habitat is typically on the ocean side of a reef, where the reef slopes down into deeper water.

(ii) Crest. The reef crest habitat is the section that joins a reef slope to the reef flat. The zone is typified by high wave energy (that is, where the waves break). It is also typified by a change in the angle of the reef from an inclined slope to a horizontal reef flat. (iii) Flat. The reef flat habitat is typically horizontal and extends back from the reef crest for 10's to 100's of metres;

(iv) Lagoon/back reef. Lagoon reef habitats are where the continuous reef flat breaks up into more patchy reef environments sheltered from wave energy. These habitats can be behind barrier/fringing reefs or within atolls. Back reef habitats are similar broken habitats where the wave energy does not typically reach the reefs and thus forms a less continuous 'lagoon style' reef habitat. Due to minimal representation among our sample, we excluded other less prevalent habitat types, such as channels and banks. To verify the sites' habitat information, we used the Millennium Coral Reef Mapping Project (MCRMP) hierarchical data ${ }^{51}$, Google Earth, and site depth information.

Productivity. We examined ocean productivity for each of our sites in $\mathrm{mg}$ of $\mathrm{C}$ per $\mathrm{m}^{2}$ per day (http://www.science.oregonstate.edu/ocean.productivity/). Using the monthly data for years 2005 to 2010 (in hdf format), we imported and converted those data into ArcGIS. We then calculated yearly average and finally an average for all these years. We used a $100 \mathrm{~km}$ buffer around each of our sites and examined the average productivity within that radius. Note that ocean productivity estimates are less accurate for near-shore environments, but we used the best available data.

Analyses. We first looked for collinearity among our covariates using bivariate correlations and variance inflation factor estimates (Extended Data Fig. 2 and Extended Data Table 4). This led to the exclusion of several covariates (not described above): (i) geographic basin (tropical Atlantic, western Indo-Pacific, central Indo-Pacific, or eastern Indo-Pacific); (ii) gross domestic product (purchasing power parity); (iii) rule of law (World Bank governance index); (iv) control of corruption (World Bank governance index); and (v) sedimentation. Additionally, we removed an index of climate stress, developed by Maina et al. ${ }^{52}$, which incorporated 11 different environmental conditions, such as the mean and variability of sea surface temperature due to repeated lack of convergence for this parameter in the model, likely indicative of unidentified multicollinearity. All other covariates had correlation coefficients 0.7 or less and variance inflation factor scores less than 5 (indicating multicollinearity was not a serious concern). Care must be taken in causal attribution of covariates that were significant in our model, but demonstrated collinearity with candidate covariates that were removed during the aforementioned process. Importantly, the covariate that exhibited the largest effect size in our model, market gravity, was not strongly collinear with other candidate covariates.

To quantify the multi-scale social, environmental, and economic factors affecting reef fish biomass we adopted a Bayesian hierarchical modelling approach that explicitly recognized the three scales of spatial organization: reef $(j)$, site $(k)$, and nation/state $(s)$.

In adopting the Bayesian approach we developed two models for inference: a null model, consisting only of the hierarchical units of observation (that is, intercepts-only) and a full model that included all of our covariates (drivers) of interest. Covariates were entered into the model at the relevant scale, leading to a hierarchical model whereby lower-level intercepts (averages) were placed in the context of higher-level covariates in which they were nested. We used the null model as a baseline against which we could ensure that our full model performed better than a model with no covariate information. We did not remove 'non-significant' covariates from the model because each covariate was carefully considered for inclusion and could therefore reasonably be considered as having an effect, even if small or uncertain; removing factors from the model is equivalent to fixing parameter estimates at exactly zero-a highly-subjective modelling decision after covariates have already been selected as potentially important ${ }^{53}$.

The full model assumed the observed, reef-scale observations of fish biomass $\left(y_{i j k s}\right)$ were modelled using a non-central $t$ distribution, allowing for fatter tails than typical log-normal models of reef fish biomass ${ }^{32}$. We chose the non-central $t$ after having initially used a log-normal model because our model diagnostics suggested that several model parameters had not converged. We ran a supplementary analysis to support our use of the non-central $t$ distribution with 3.5 degrees of freedom (see Supplementary Information). Therefore our model was:

$$
\begin{gathered}
\log \left[y_{i j k s}\right] \sim \text { non-central } t\left(\mu_{i j k s}, \tau_{\text {reef }}, 3.5\right) \\
\mu_{i j k s}=\beta_{0 j k s}+\beta_{\text {reef }} \boldsymbol{X}_{\text {reef }} \\
\tau_{\text {reef }} \sim \mathrm{U}(0,100)^{-2}
\end{gathered}
$$

with $\boldsymbol{X}_{\text {reef }}$ representing the matrix of observed reef-scale covariates and $\beta_{\text {reef }}$ array of estimated reef-scale parameters. The $\tau_{\text {reef }}$ (and all subsequent $\tau$ values) were assumed common across observations in the final model and were minimally 
informative ${ }^{53}$. Using a similar structure, the reef-scale intercepts $\left(\beta_{0 j k s}\right)$ were structured as a function of site-scale covariates $\left(\boldsymbol{X}_{\text {sit }}\right)$ :

$$
\begin{gathered}
\beta_{0 j k s} \sim \mathrm{N}\left(\mu_{j k s}, \tau_{\text {sit }}\right) \\
\mu_{j k s}=\gamma_{0 k s}+\gamma_{\text {sit }} \boldsymbol{X}_{\text {sit }} \\
\tau_{\text {sit }} \sim \mathrm{U}(0,100)^{-2}
\end{gathered}
$$

with $\gamma_{\text {sit }}$ representing an array of site-scale parameters. Building upon the hierarchy, the site-scale intercepts $\left(\gamma_{0 k s}\right)$ were structured as a function of state-scale covariates $\left(\boldsymbol{X}_{\text {sta }}\right)$ :

$$
\begin{gathered}
\gamma_{0 k s} \sim \mathrm{N}\left(\mu_{k s}, \tau_{\text {sta }}\right) \\
\mu_{k s}=\gamma_{0}+\gamma_{\text {sta }} \boldsymbol{X}_{\text {sta }} \\
\tau_{\text {sta }} \sim \mathrm{U}(0,100)^{-2}
\end{gathered}
$$

Finally, at the top scale of the analysis we allowed for a global (overall) estimate of average $\log$-biomass $\left(\gamma_{0}\right)$ :

$$
\gamma_{0} \sim \mathrm{N}(0.0,1000)
$$

The relationships between fish biomass and reef, site, and state-scale drivers was carried out using the PyMC package ${ }^{54}$ for the Python programming language, using a Metropolis-Hastings (MH) sampler run for $10^{6}$ iterations, with a 900,000 iteration burn-in thinned by 10 , leaving 10,000 samples in the posterior distribution of each parameter; these long burn-in times are often required with a complex model using the $\mathrm{MH}$ algorithm. Convergence was monitored by examining posterior chains and distributions for stability and by running multiple chains from different starting points and checking for convergence using Gelman-Rubin statistics ${ }^{55}$ for parameters across multiple chains; all were at or close to 1 , indicating good convergence of parameters across multiple chains.

Overall model fit. We conducted posterior predictive checks for goodness of fit (GoF) using Bayesian $P$ values ${ }^{43}(\mathrm{BpV})$, whereby fit was assessed by the discrepancy between observed or simulated data and their expected values. To do this we simulated new data $\left(y_{i}^{\text {new }}\right)$ by sampling from the joint posterior of our model $(\theta)$ and calculated the Freeman-Tukey measure of discrepancy for the observed $\left(y_{i}{ }^{\text {obs }}\right)$ or simulated data, given their expected values $\left(\mu_{i}\right)$ :

$$
D(y \mid \theta)=\sum_{i}\left(\sqrt{y_{i}}-\sqrt{y_{i}}\right)^{2}
$$

yielding two arrays of median discrepancies $D\left(y^{\text {obs }} / \theta\right)$ and $D\left(y^{\text {new }} / \theta\right)$ that were then used to calculate a $\mathrm{BpV}$ for our model by recording the proportion of times $D\left(y^{\mathrm{obs}} / \theta\right)$ was greater than $D\left(y^{\text {new }} / \theta\right)$ (Extended Data Fig. 3a). A BpV above 0.975 or under 0.025 provides substantial evidence for lack of model fit. Evaluated by the deviance information criterion (DIC), the full model greatly outperformed a null model that included no covariates $(\triangle \mathrm{DIC}=472)$.

To examine homoscedasticity, we checked residuals against fitted values. We also checked the residuals against all covariates included in the model, and several covariates that were not included in the model (primarily due to collinearity), including: (i) Atoll, a binary metric of whether the reef was on an atoll or not; (ii) control of corruption, perceptions of the extent to which public power is exercised for private gain, including both petty and grand forms of corruption, as well as 'capture' of the state by elites and private interests, derived from the World Bank survey on governance; (iii) geographic basin, whether the site was in the tropical Atlantic, western Indo-Pacific, central Indo-Pacific, or eastern Indo-Pacific; (iv) connectivity, we examined three measures based on the area of coral reef within a $30 \mathrm{~km}, 100 \mathrm{~km}$, and $600 \mathrm{~km}$ radius of the site; (v) sedimentation; (vi) coral cover (which was only available for a subset of the sites); (vii) climate stress ${ }^{52}$; and (viii) census method. The model residuals showed no patterns with these eight additional covariates, suggesting they would not explain additional information in our model.

Bright and dark spot estimates. Because the performance of site scale locations are of substantial interest in uncovering novel solutions for reef conservation, we defined bright and dark spots at the site scale. To this end, we defined bright (or dark) spots as locations where expected site-scale intercepts $\left(\gamma_{0 k s}\right)$ differed by more than two standard deviations from their nation/state-scale expected value $\left(\mu_{k s}\right)$, given all the covariates present in the full hierarchical model:

$$
\mathrm{SS}_{\text {spot }}=\left|\left(\mu_{k s}-\gamma_{0 k s}\right)\right|>2\left[\text { s.d. }\left(\mu_{k s}-\gamma_{0 k s}\right)\right]
$$

This, in effect, probabilistically identified the most deviant sites, given the model, while shrinking sites towards their group-level means, thereby allowing us to overcome potential bias due to low and varying sample sizes that can lead to extreme values from chance alone. After an initial log-normal model formulation, where we were not confident in model convergence, we employed a non-central $t$ distribution at the observation scale, which facilitated model convergence and dampened any effects of potentially extreme reef-scale observations on the bright and dark spot estimates. Further, we did not consider a site a bright or dark spot if the group-level (that is, nation/state) mean included fewer than five sites.

Analysing conditions at bright spots. For our preliminary exploration into why bright and dark spots may diverge from expectations, we surveyed data providers and other experts about key social, institutional, and environmental conditions at the 15 bright spots, 35 dark spots, and 14 sites that performed most closely to model specifications. Specifically, we developed an online survey (SI) using Survey Monkey (http://www.surveymonkey.com) software, which we asked data providers who sampled those sites to complete with input from local experts, where necessary. Data providers generally filled in the survey in consultation with nationally based field team members who had detailed local knowledge of the socioeconomic and environmental conditions at each of the sites. Research on bright spots in agricultural development ${ }^{19}$ highlights several types of social and environmental conditions that may lead to bright spots, which we adapted and developed proxies for as the basis of our survey into why our bright and dark spots may diverge from expectations. These include:

(i) Social and institutional conditions. We examined the presence of customary management institutions such as taboos and marine tenure institutions, whether there was substantial engagement by local people in management (specifically defined as there being active engagement by local people in reef management decisions; token involvement and consultation were not considered substantial engagement), and whether there were high levels of dependence on marine resources (specifically, whether a majority of local residents depend on reef fish as a primary source of food or income). All social and institutional conditions were converted to presence/absence data. Dependence on resources and engagement were limited to sites that had adjacent human populations. All other conditions were recorded regardless of whether there is an adjacent community.

(ii) Technological use/innovation. We examined the presence of motorized vessels, intensive capture equipment (such as beach seine nets, surround gill nets, and muro-ami nets), and storage capacity (that is, freezers).

(iii) External influences (such as donor-driven projects). We examined the presence of NGOs, fishery development projects, development initiatives (such as alternative livelihoods), and fisheries improvement projects. All external influences were recorded as present/absent then summarized into a single index of whether external projects were occurring at the site.

(iv) Environmental/ecological processes (for example, recruitment and connectivity). We examined whether sites were within $5 \mathrm{~km}$ of mangroves and deep-water refuges, and whether there had been any major environmental disturbances such as coral bleaching, tsunami, and cyclones within the past 5 years. All environmental conditions were recorded as present/absent.

As an exploratory analysis of associations between these conditions and whether sites diverged more or less from expectations, we used two complementary approaches. The link between the presence/absence of the aforementioned conditions and whether a site was bright, average, or dark was assessed using a Fisher's exact test. Then we tested whether the mean deviation in fish biomass from expected was similar between sites with presence or absence of the mechanisms in question (that is, the presence or absence of marine tenure/taboos) using an ANOVA assuming unequal variance. The two tests yielded similar results, but provide slightly different ways to conceptualize the issue, the former is correlative while the latter explains deviation from expectations based on conditions, so we provide both (Fig. 3 and Extended Data Fig. 4). It is important to note that some of these social and environmental conditions were significantly associated (that is, Fisher's exact probabilities $<0.05$ ), and further research is required to uncover how these and other conditions may make sites bright or dark.

31. Daw, T. et al. The Spatial Behaviour of Artisanal Fishers: Implications for Fisheries Management and Development (Fishers in Space). (WIOMSA, 2011)

32. MacNeil, M. A. et al. Recovery potential of the world's coral reef fishes. Nature 520, 341-344 (2015).

33. Mora, C. et al. Global human footprint on the linkage between biodiversity and ecosystem functioning in reef fishes. PLoS Biol. 9, e1000606 (2011).

34. Edwards, C. B. et al. Global assessment of the status of coral reef herbivorous fishes: evidence for fishing effects. Proc. Biol. Sci. 281, 20131835 (2014)

35. Froese, R. \& Pauly, D. FishBase. http://www.fishbase.org (2014).

36. Center for International Earth Science Information Network (CIESIN). Gridded population of the world. Version 3 (GPWv3) http://sedac.ciesin.columbia.edu/ gpw (2005). 
37. MacNeil, M. A. \& Connolly, S. R. in Ecology of Fishes on Coral Reefs (ed C. Mora) Ch. 12, 116-126 (2015).

38. Mora, C. et al. Ecology. Coral reefs and the global network of Marine Protected Areas. Science 312, 1750-1751 (2006).

39. Ravenstein, E. G. The laws of migration. J. R. Stat. Soc. 48, 167-235 (1885).

40. Anderson, J. E. A theoretical foundation for the gravity equation. Am. Econ. Rev. 69, 106-116 (1979).

41. Anderson, J. E. The Gravity Model. (National Bureau of Economic Research, 2010).

42. Lukermann, F. \& Porter, P. W. Gravity and potential models in economic geography. Ann. Assoc. Am. Geogr. 50, 493-504 (1960).

43. Nelson, A. Travel Time to Major Cities: A Global Map of Accessibility. (Ispra, Italy, 2008).

44. Bartholomé, E. et al. GLC 2000: Global Land Cover Mapping for the Year 2000: Project Status November 2002. (Institute for Environment and Sustainability, 2002).

45. R Core Team. R: A language and environment for statistical computing. https://www.R-project.org (2016).

46. Dijkstra, E. W. A note on two problems in connexion with graphs. Numer. Math. 1, 269-271 (1959).
47. Black, W. R. An analysis of gravity model distance exponents. Transportation 2, 299-312 (1973).

48. Emran, M. S. \& Shilpi, F. The Extent of the Market and Stages of Agricultural Specialization. Vol. 4534 (World Bank Publications, 2008).

49. Cinner, J. E., Graham, N. A., Huchery, C. \& Macneil, M. A. Global effects of local human population density and distance to markets on the condition of coral reef fisheries. Conserv. Biol. 27, 453-458 (2013).

50. Teh, L. S. L., Teh, L. C. \& Sumaila, U. R. A Global Estimate of the Number of Coral Reef Fishers. PLoS One 8, e65397 (2013).

51. Andréfouët, S. et al. in 10th International Coral Reef Symposium (eds Y. Suzuk et al.) 1732-1745 (Japanese Coral Reef Society, 2006).

52. Maina, J., McClanahan, T. R., Venus, V., Ateweberhan, M. \& Madin, J. Global gradients of coral exposure to environmental stresses and implications for local management. PLoS One 6, e23064 (2011).

53. Gelman, A. et al. Bayesian Data Analysis. Vol. 2 (Taylor \& Francis, 2014).

54. Patil, A., Huard, D. \& Fonnesbeck, C. J. PyMC: Bayesian stochastic modelling in Python. J. Stat. Softw. 35, 1-81 (2010)

55. Gelman, A. \& Rubin, D. B. Inference from iterative simulation using multiple sequences. Stat. Sci. 7, 457-472 (1992) 


\section{RESEARCH LETTER}
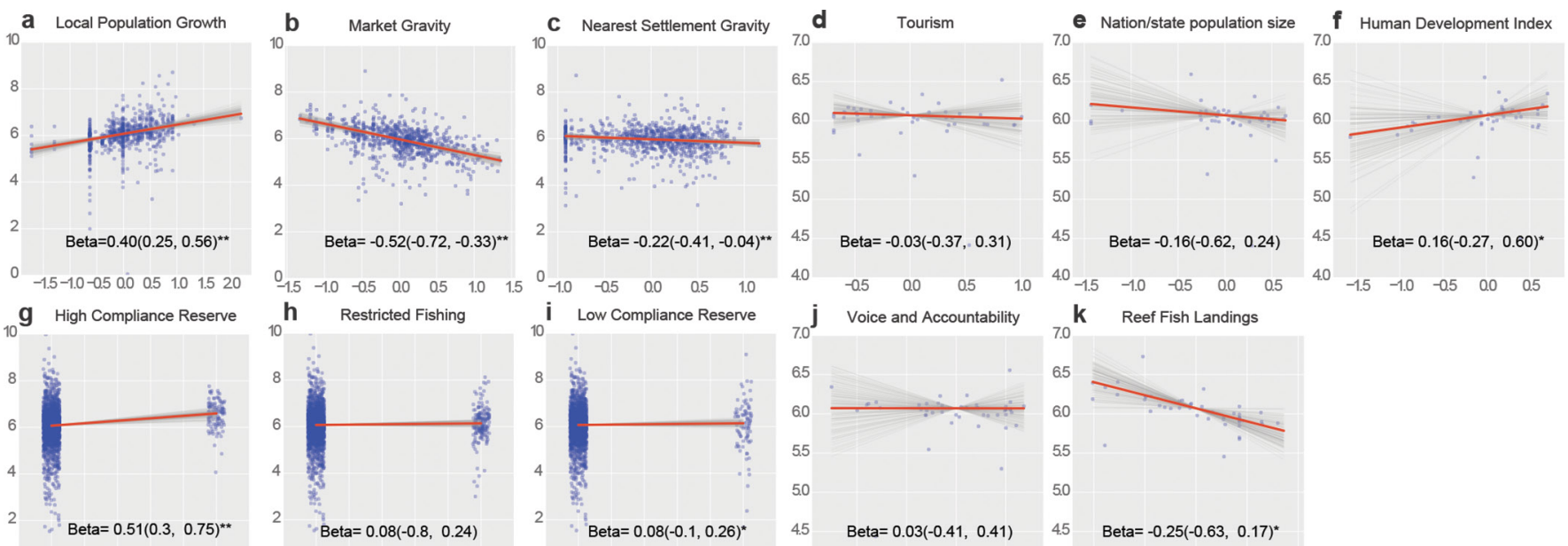

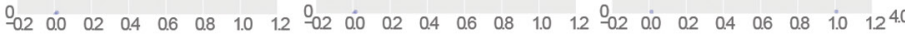
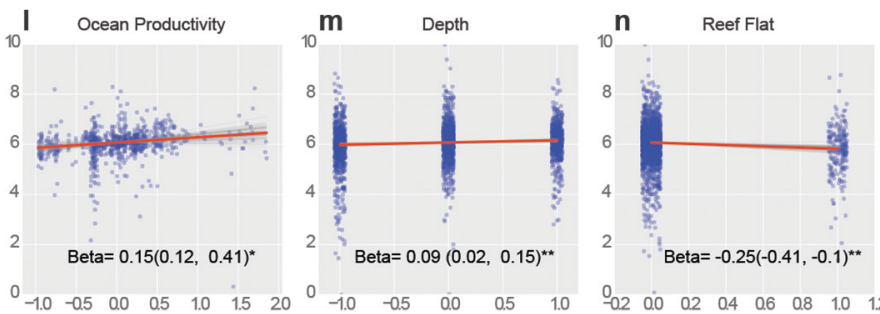

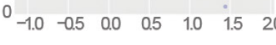

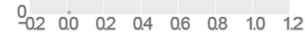

Extended Data Figure 1 | Marginal relationships between reef fish biomass and social drivers. $\mathbf{a}$, Local population growth; $\mathbf{b}$, market gravity; c, nearest settlement gravity; d, tourism; e, nation/state population size; f, Human Development Index; $\mathbf{g}$, high compliance marine reserve ( 0 is fished baseline); $\mathbf{h}$, restricted fishing ( 0 is fished baseline); $\mathbf{i}$, low-compliance marine reserve (0 is fished baseline); $\mathbf{j}$, voice and accountability; $\mathbf{k}$, reef fish landings; $\mathbf{l}$, ocean productivity; $\mathbf{m}$, depth $(-1=0-4 \mathrm{~m}, 0=4-10 \mathrm{~m}, 1=>10 \mathrm{~m}) ; \mathbf{n}$, reef flat ( 0 is reef slope baseline); $\mathbf{o}$, reef crest flat ( 0 is reef slope baseline); $\mathbf{p}$, lagoon/back reef flat ( 0 is reef

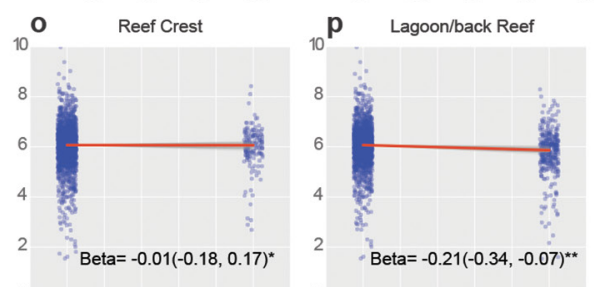

slope baseline). All variables displayed on the $x$ axis are standardized. Red lines are the marginal trend line for each parameter as estimated by the full model. Grey lines are 100 simulations of the marginal trend line sampled from the posterior distributions of the intercept and parameter slope, analogous to conventional confidence intervals. Two asterisks indicate that $95 \%$ of the posterior density is in either a positive or negative direction (Fig. $1 \mathrm{~b}-\mathrm{d}$ ); a single asterisk indicates that $75 \%$ of the posterior density is in either a positive or negative direction. 


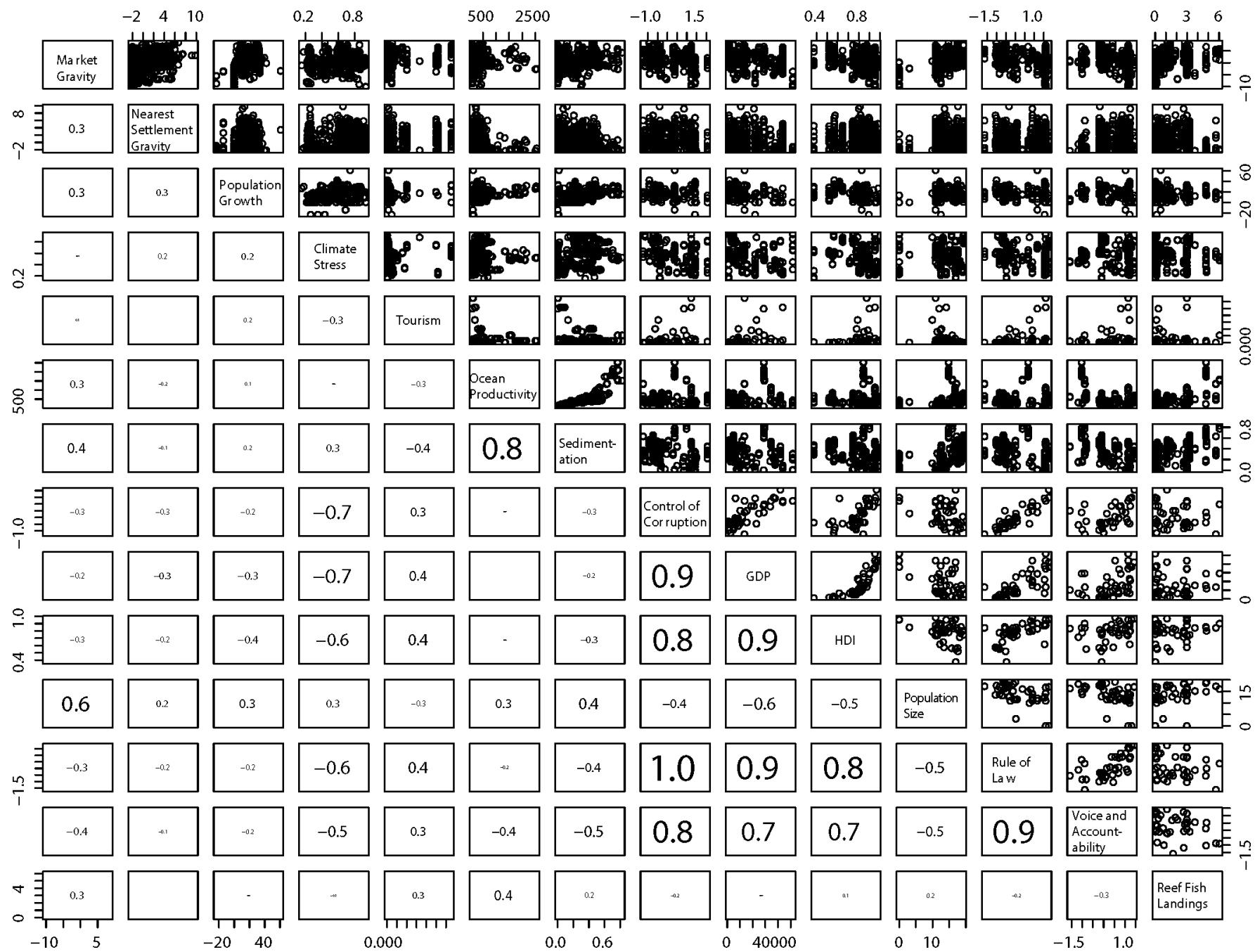

Extended Data Figure 2 | Correlation plot of candidate continuous covariates before accounting for collinearity (Extended Data Table 4).

Collinearity between continuous and categorical covariates (including biogeographic region, habitat, protection status, and depth) were analysed using box plots. 

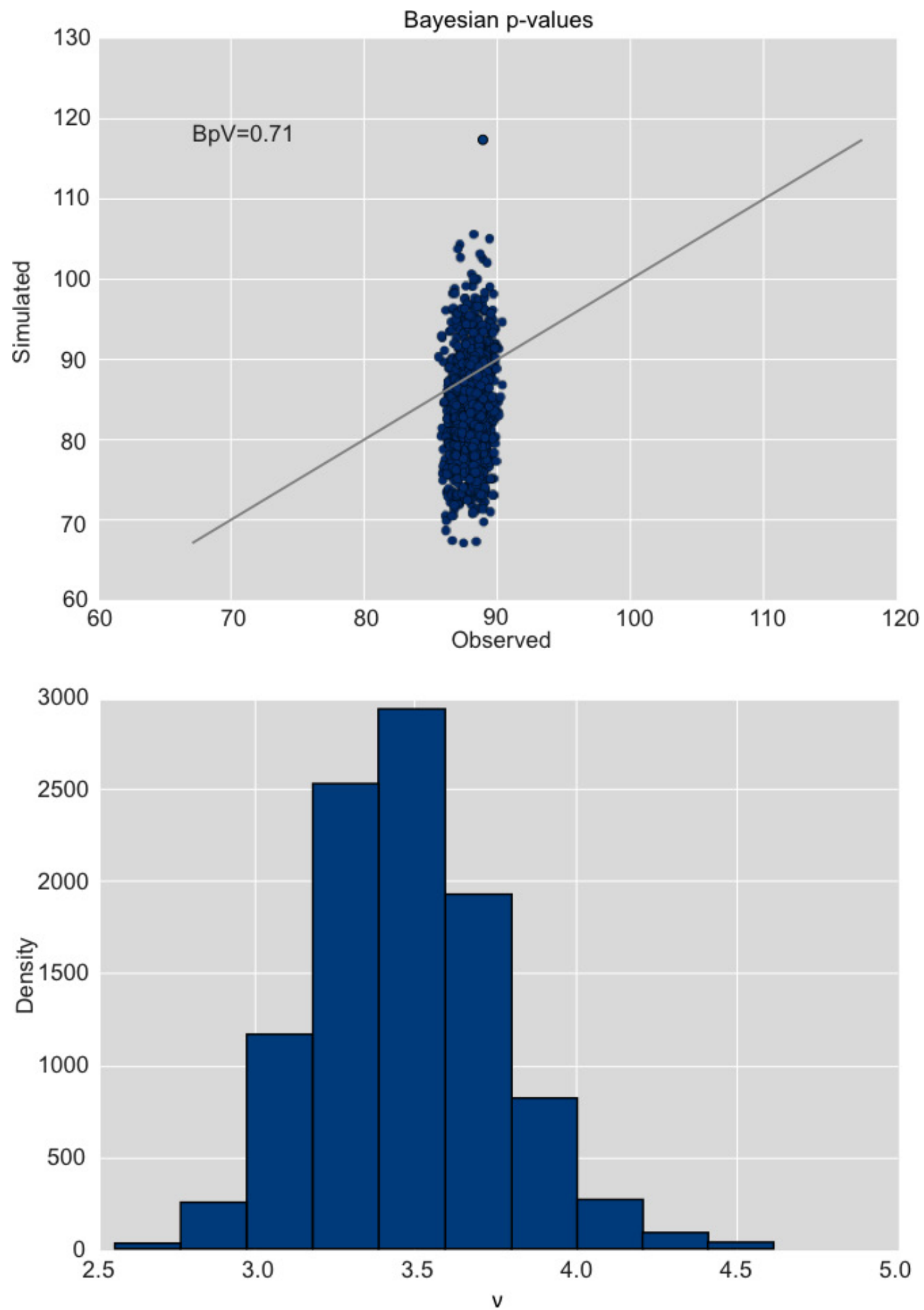

Extended Data Figure 3 | Model fit statistics. Top, Bayesian $P$ values (BpV) for the full model indicating goodness of fit, based on posterior discrepancy. Points are Freeman-Tukey differences between observed and expected values, and simulated and expected values within the MCMC scheme $(n=10,000)$. Plot shows no evidence for lack of fit between the model

and the data. Bottom, Posterior distribution for the degrees of freedom parameter $(\nu)$ in our supplementary analysis of candidate distributions. The highest posterior density of 3.46 , with $97.5 \%$ of the total posterior density below 4 provides strong evidence in favour of a non-central $t$ distribution relative to a normal distribution and supports the use of 3.5 for $\nu$. 


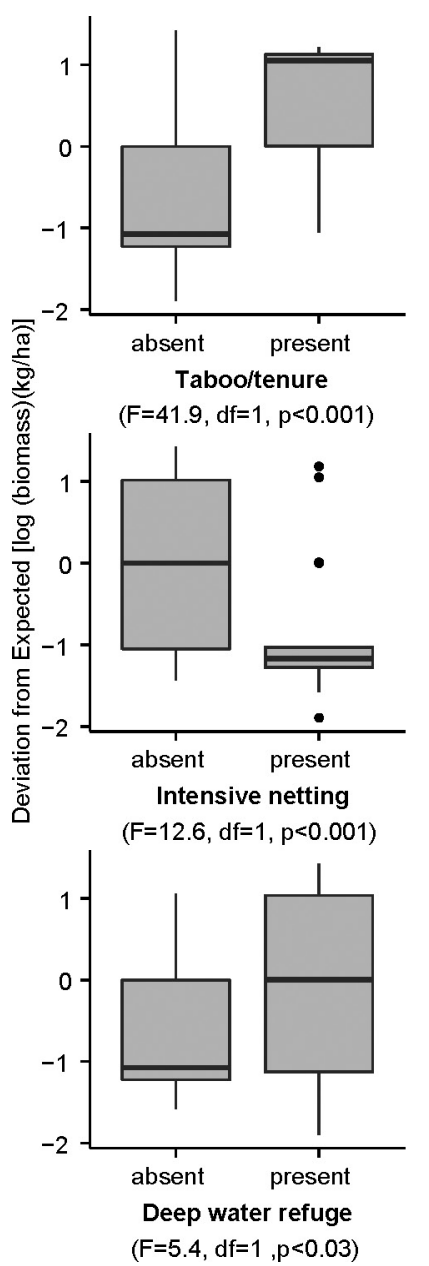

Extended Data Figure 4 | Box plot of deviation from expected as a function of the presence or absence of key social and environmental conditions expected to produce bright spots. Boxes range from the first to third quartile and whiskers extend to the highest value that is within
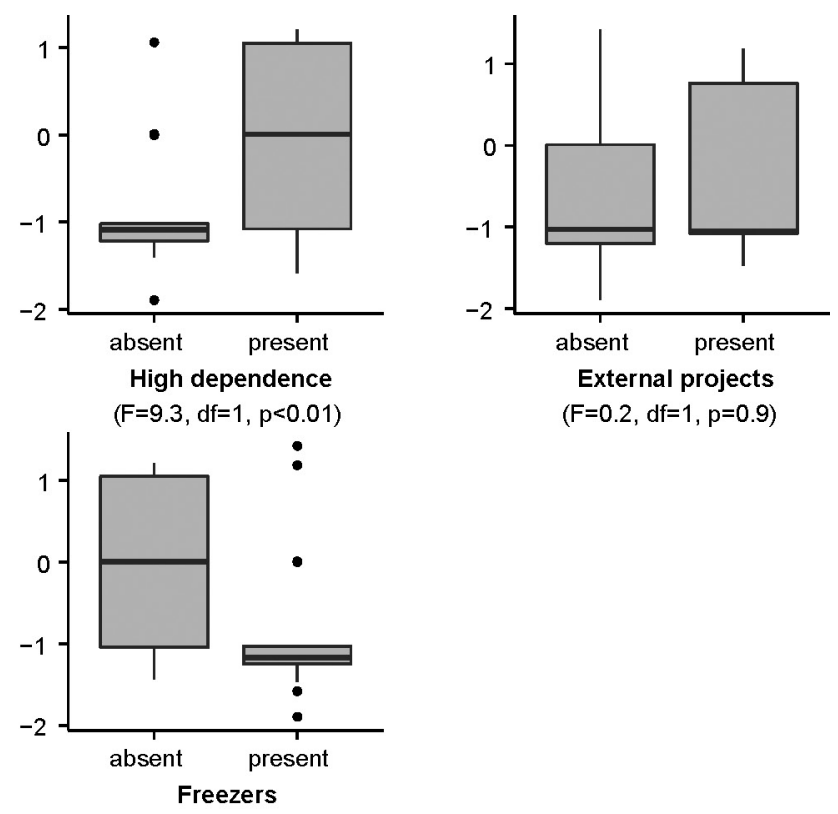

External projects
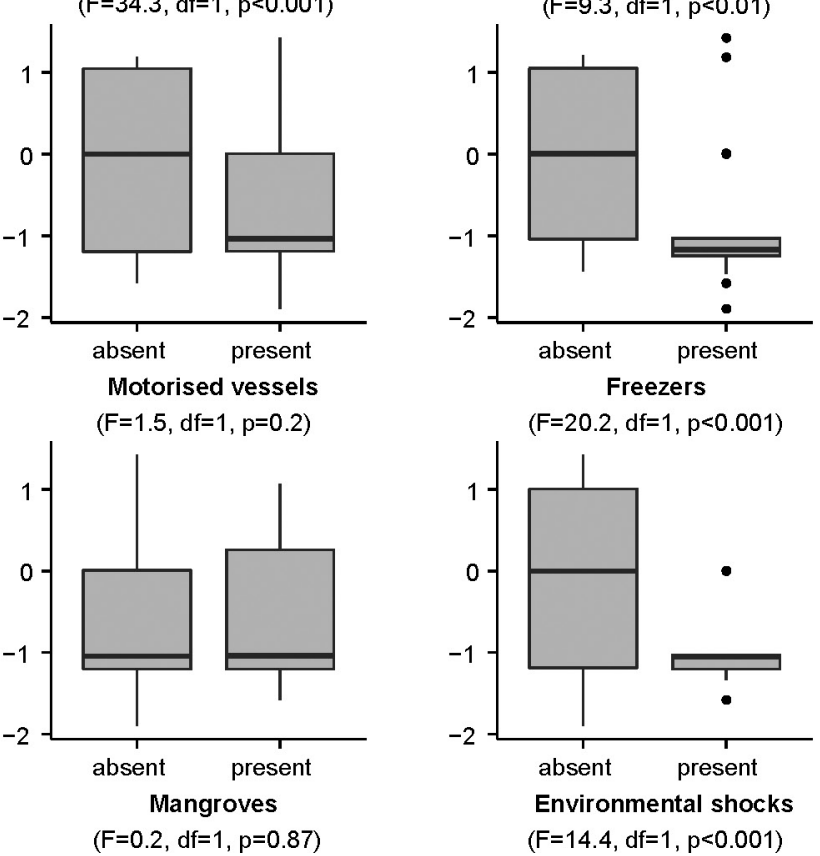

$1.5 \times$ the inter-quartile range (that is, distance between the first and third quartiles). Data beyond the end of the whiskers are outliers, which are plotted as points. 


\section{RESEARCH LETTER}

Extended Data Table 1 | Summary of social and environmental covariates

$\begin{array}{llll}\text { Covariate } & \text { Description } & \text { Scale } & \text { Key data sources }\end{array}$

Local population growth

Difference in local human population (i.e. 100km buffer around our sites) between 2000-2010

'Gravity' of major markets within $500 \mathrm{~km}$

'Gravity' of the closest

human settlement

Protection status

Human Development index

Population Size

Tourism

Voice and accountability

Perceptions of the extent to which a country's citizens are able to participate in selecting their government.

Landings of reef fish (tons) per $\mathrm{Km}^{2}$ of reef

Fish landings

Productivity

The average (2005-2010) ocean productivity in $\mathrm{mg} \mathrm{C/} \mathrm{m} 2$ /

day

Habitat

Whether the reef is a slop, crest, flat, or back reef/lagoon

Depth of the ecological survey $(<4 \mathrm{~m}, 4.1-10 \mathrm{~m},>10 \mathrm{~m})$

Depth
Site

Socioeconomic Data and Application Centre (SEDAC) gridded population of the work database ${ }^{36}$

Human population size, land cover, road networks, coastlines

Human population size, land cover, road networks, coastlines

Reef Expert opinion, global map of marine protected areas.

Nation/state United Nations Development Programme

$\begin{array}{ll}\begin{array}{l}\text { Nation/ } \\ \text { state }\end{array} & \text { World Bank, census estimates, Wikipedia } \\ \begin{array}{l}\text { Nation/ } \\ \text { state }\end{array} & \begin{array}{l}\text { World Tourism Organization's Compendium of Tourism } \\ \text { Statistics, census estimates }\end{array} \\ \text { Nation/ } & \text { World Bank } \\ \text { state } & \\ \text { Nation/ } & \text { Teh et al. }{ }^{50} \\ \text { state } & \\ \text { Site } & \text { http://www.science.oregonstate.edu/ocean.productivity/ } \\ & \\ \text { Reef } & \text { Primary data } \\ \text { Reef } & \text { Primary data }\end{array}$

Further details can be found in the Methods. The smallest scale is the individual reef. Sites consist of clusters of reefs within $4 \mathrm{~km}$ of each other. Nations/states generally correspond to countries, but can also include or territories or states, particularly when geographically isolated (for example, Hawaii). Refs 36 and 50 are cited in this table. 


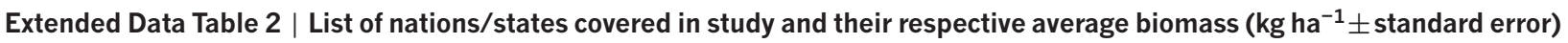

\begin{tabular}{|c|c|c|}
\hline Nation/states & Average biomass & $( \pm \mathrm{SE})$ \\
\hline American Samoa & 235.93 & $( \pm 17.75)$ \\
\hline Australia & 735.01 & $( \pm 136.85)$ \\
\hline Belize & 981.16 & $( \pm 65.32)$ \\
\hline Brazil & 663.35 & $( \pm 115.17)$ \\
\hline British Indian Ocean Territory (Chagos) & 2975.58 & $( \pm 603.99)$ \\
\hline Cayman Islands & 464.09 & $( \pm 25.41)$ \\
\hline Colombia & 846.07 & $( \pm 162.49)$ \\
\hline Commonwealth of the Northern Mariana Islands & 505.54 & $( \pm 99.3)$ \\
\hline Comoros Islands & 305.62 & $( \pm 38.73)$ \\
\hline Cuba & 2107.37 & $( \pm 466.34)$ \\
\hline Egypt & 552.73 & $( \pm 70.18)$ \\
\hline Farquhar & 2665.48 & $( \pm 492.62)$ \\
\hline Federated States of Micronesia & 377.90 & $N A(n=1)$ \\
\hline Fiji & 1464.54 & $( \pm 144.39)$ \\
\hline Florida & 1661.35 & $( \pm 198.42)$ \\
\hline French Polynesia & 1077.20 & $( \pm 101.4)$ \\
\hline Guam & 118.98 & $( \pm 16.81)$ \\
\hline Hawaii & 380.45 & $( \pm 25.11)$ \\
\hline Indonesia & 275.76 & $( \pm 19.89)$ \\
\hline Israel & 445.16 & $( \pm 105.13)$ \\
\hline Jamaica & 275.77 & $( \pm 50.75)$ \\
\hline Kenya & 335.25 & $( \pm 65.81)$ \\
\hline Kiribati & 1219.93 & $( \pm 93.2)$ \\
\hline Madagascar & 409.48 & $( \pm 46.1)$ \\
\hline Maldives & 688.64 & $( \pm 97.07)$ \\
\hline Marshall Islands & 707.72 & $( \pm 174.38)$ \\
\hline Mauritius & 166.93 & $( \pm 73.7)$ \\
\hline Mayotte & 631.43 & $( \pm 68.25)$ \\
\hline Mexico & 1930.81 & $( \pm 737.09)$ \\
\hline Mozambique & 461.01 & $( \pm 60.14)$ \\
\hline Netherlands Antilles & 428.01 & $( \pm 53.99)$ \\
\hline New Caledonia & 1460.27 & $( \pm 143.18)$ \\
\hline NW Hawaiian Islands & 729.71 & $( \pm 46.33)$ \\
\hline Oman & 282.79 & $( \pm 70.22)$ \\
\hline Palau & 3212.26 & $( \pm 332.02)$ \\
\hline Panama & 373.78 & $( \pm 85.41)$ \\
\hline Papua New Guinea & 566.70 & $( \pm 31.76)$ \\
\hline Philippines & 202.62 & NA $(n=1)$ \\
\hline Pacific Remote Island Areas (PRIA), USA & 641.47 & $( \pm 79.25)$ \\
\hline Reunion & 172.32 & $( \pm 30.67)$ \\
\hline Seychelles & 446.99 & $( \pm 46.6)$ \\
\hline Solomon Islands & 1280.30 & $( \pm 216.74)$ \\
\hline Tanzania & 346.29 & $( \pm 41.51)$ \\
\hline Tonga & 1149.97 & $( \pm 151.27)$ \\
\hline United Arab Emirates & 81.35 & $( \pm 28.66)$ \\
\hline Venezuela & 1472.39 & $( \pm 496.95)$ \\
\hline
\end{tabular}

In most cases, nation/state refers to an individual country, but can also include states (for example, Hawaii or Florida), territories (for example, British Indian Ocean Territory), or other jurisdictions. We treated the northwestern Hawaiian islands and Farquhar as separate 'nation/states' from Hawaii and the Seychelles, respectively, because they are extremely isolated and have little or no human population. In practical terms, this meant different values for a few nation/state scale indicators that ended up having relatively small effect sizes (Fig. $1 \mathrm{~b}$ ): population, tourism visitations, and in the case of the northwestern Hawaiian islands, fish landings. 


\section{RESEARCH LETTER}

Extended Data Table 3 | Model selection of potential gravity indicators and components

\begin{tabular}{llrr}
\hline Model & Covariates & AlC & Delta AIC \\
\hline M2 & Gravity of nearest city & 2666.4 & 0 \\
M1 & Gravity of all cities in $500 \mathrm{~km}$ & 2669.5 & 3.1 \\
M3 & Travel time to nearest city & 2700.0 & 33.6 \\
M5 & Gravity of nearest small peri-urban area (40 people $/ \mathrm{km} 2)$ & 2703.9 & 37.5 \\
M11 & Total Population in 500km radius & 2712.0 & 45.6 \\
M9 & Travel time to the nearest large peri-urban area (75 people $/ \mathrm{km} 2)$ & 2712.1 & 45.7 \\
M6 & Travel time to nearest small peri-urban area (40 people $/ \mathrm{km} 2)$ & 2713.8 & 47.4 \\
M8 & Gravity to the nearest large peri-urban area $(75$ people $/ \mathrm{km} 2)$ & 2722.9 & 56.5 \\
M7 & Population of nearest small peri-urban area (40 people/ $/ \mathrm{km} 2)$ & 2792.7 & 126.3 \\
M4 & Population of the nearest city & 2812.8 & 146.5 \\
M10 & Population of the nearest large peri-urban area $(75$ people $/ \mathrm{km} 2)$ & 2822.2 & 155.8 \\
M0 & Intercept only & 2827.7 & 161.27 \\
\hline
\end{tabular}


Extended Data Table 4 | Variance inflation factor (VIF) scores for continuous data before and after removing variables due to collinearity

\begin{tabular}{lrr}
\hline Covariate & starting VIF & ending VIF \\
\hline Market gravity (log) & 1.9 & 1.5 \\
Nearest settlement gravity & 1.4 & 1.3 \\
Population growth & 1.4 & 1.3 \\
Climate stress & 2.7 & $\mathrm{X}$ \\
Ocean productivity & 6.5 & 2.2 \\
Sedimentation & 6.0 & $\mathrm{X}$ \\
Tourism & 2.5 & 2.0 \\
Control Corruption & 10.5 & $\mathrm{X}$ \\
GDP & 8.2 & $\mathrm{X}$ \\
HDI & 5.5 & 3.3 \\
Population size & 1.9 & 1.8 \\
Reef fish landings & 3.1 & 2.2 \\
Rule of Law & 33.8 & $\mathrm{X}$ \\
Voice and Accountability & 3.2 & 3.2 \\
\hline X-covariate removed & &
\end{tabular}

$\mathrm{X}=$ covariate removed. 


\section{RESEARCH LETTER}

Extended Data Table 5 | List of bright and dark spot locations, population status, and protection status

\begin{tabular}{|c|c|c|c|c|}
\hline $\begin{array}{l}\text { Bright or } \\
\text { Dark }\end{array}$ & Nation/State & Location & Populated & Protection \\
\hline \multirow{15}{*}{ Bright } & British Indian Ocean Territory & Chagos & Unpopulated & $\begin{array}{l}\text { Unfished (high } \\
\text { compliance) }\end{array}$ \\
\hline & \multirow{2}{*}{$\begin{array}{l}\text { Commonwealth of the Northern Mariana } \\
\text { Islands }\end{array}$} & Agrihan & Unpopulated & Fished \\
\hline & & Guguan & Unpopulated & Fished \\
\hline & \multirow{3}{*}{ Indonesia } & Raja Ampat 1 & Populated & Restricted \\
\hline & & Raja Ampat 2 & Populated & Restricted \\
\hline & & Kalimantan & Populated & Restricted \\
\hline & \multirow{2}{*}{ Kiribati } & Tabueran 1 & Populated & Fished \\
\hline & & Tabueran 2 & Populated & Fished \\
\hline & Papua New Guinea & Karkar & Populated & Restricted \\
\hline & \multirow{2}{*}{ PRIA } & Baker & Unpopulated & Restricted \\
\hline & & Jarvis Island & Unpopulated & Restricted \\
\hline & \multirow{4}{*}{ Solomon Islands } & Choiseul & Populated & Fished \\
\hline & & Isabel & Populated & Fished \\
\hline & & Makira & Populated & Fished \\
\hline & & New Georgia & Populated & Fished \\
\hline \multirow{35}{*}{ Dark } & Australia & Lord Howe & Populated & $\begin{array}{l}\text { Unfished (high } \\
\text { compliance) }\end{array}$ \\
\hline & \multirow{13}{*}{ Hawaii } & Hawaii & Populated & Fished \\
\hline & & Kauai 1 & Populated & Fished \\
\hline & & Kauai 2 & Populated & Fished \\
\hline & & Lanai & Populated & Fished \\
\hline & & Maui 1 & Populated & Fished \\
\hline & & Maui 2 & Populated & Fished \\
\hline & & Molokai & Populated & Fished \\
\hline & & Oahu 1 & Populated & Fished \\
\hline & & Oahu 2 & Populated & Fished \\
\hline & & Oahu 3 & Populated & Fished \\
\hline & & Oahu 4 & Populated & Fished \\
\hline & & Oahu 5 & Populated & Fished \\
\hline & & Oahu 6 & Populated & Fished \\
\hline & \multirow{4}{*}{ Indonesia } & Karimunjawa 1 & Populated & Fished \\
\hline & & Karimunjawa 2 & Populated & Unfished (low compliance) \\
\hline & & Karimunjawa 3 & Populated & Unfished (low compliance) \\
\hline & & Pulau Aceh & Populated & Fished \\
\hline & \multirow{3}{*}{ Jamaica } & Montego Bay 1 & Populated & Unfished (low compliance) \\
\hline & & Montego Bay 2 & Populated & Fished \\
\hline & & Rio Bueno & Populated & Fished \\
\hline & Kenya & Diani & Populated & Fished \\
\hline & Madagascar & Toliara & Populated & Fished \\
\hline & \multirow{2}{*}{ Mauritius } & Anse Raie & Populated & Fished \\
\hline & & Grand Sable & Populated & Fished \\
\hline & \multirow{3}{*}{ NW Hawaii } & Lisianski & Unpopulated & $\begin{array}{l}\text { Unfished (high } \\
\text { compliance) }\end{array}$ \\
\hline & & Pearl \& Hermes 1 & Unpopulated & $\begin{array}{l}\text { Unfished (high } \\
\text { compliance) }\end{array}$ \\
\hline & & Pearl \& Hermes 2 & Unpopulated & $\begin{array}{l}\text { Unfished (high } \\
\text { compliance) }\end{array}$ \\
\hline & Reunion & Reunion & Populated & Fished \\
\hline & Seychelles & Bel Ombre & Populated & Restricted \\
\hline & \multirow{4}{*}{ Tanzania } & Bongoyo & Populated & $\begin{array}{l}\text { Unfished (high } \\
\text { compliance) }\end{array}$ \\
\hline & & Chapwani & Populated & Fished \\
\hline & & Mtwara & Populated & Fished \\
\hline & & $\begin{array}{l}\text { Stone Town, } \\
\text { Zanzibar }\end{array}$ & Populated & Fished \\
\hline & Venezuela & Chuspa & Populated & Fished \\
\hline
\end{tabular}

